\title{
Importance and Impact of Ecological Approaches to Crop Domestication
}

\author{
Temesgen Begna \\ Chiro National Sorghum Research and Training Centre, P.O.BOX 190, Chiro, Ethiopia
}

\begin{abstract}
Domestication is the sign of the beginning of agriculture and it is the outcome of a selection process that leads to increased adaptation of crop plants from wild relatives to mitigate the effect of food security problems. Plant breeding primarily based on domestication to facilitate the introgression of adaptive diversity, providing breeders with new tools for crop improvement through drought, insect, and disease-resistant varieties. In the domestication process, significant alteration in phenological, morphological and genetical leads to the increased adaptation and use of the plants under the strategic and modern plant breeding practices. The transformation of wild species into elite cultivars through domestication entails evolutionary responses in which plant populations adapt to selection. Selection and plant breeding has reduced genetic variation in all crop species because limited number of preferred crop plants selected for further improvements for different desirable traits. Therefore, novel variation can be introduced from wild relatives and variation will be useful in crop improvement by either traditional breeding methods or biotechnology. Domestication syndrome is a group of traits that can arise through human preferences for ease of harvest and growth under human management. Domestication focuses on genetic variation, as well as new genetic variation introduced via mutation or introgression. Domestication has been contributing in overcoming the global food challenges and addressing the problem of yield reduction and its links with pest management. Domestication leads to the development of modern cultivars, which have contributed to the dramatic improvement of yield of the crops for the world. It is now believed that plant domestication was much more complex in evolutionary terms and of wider geographical extent than previously believed. Crop plants have been domesticated over vast areas and not in more restricted geographical areas as the center of origin. Generally, the practice of improving crop production through bringing the wild plants to controlled management plays great roles to alleviate poverty and raise the living standards of the peoples.
\end{abstract}

Keywords: Crop; Domestication; Evolution; Ecology; Center of origin; Environment

DOI: $10.7176 / \mathrm{JBAH} / 10-8-04$

Publication date: April $30^{\text {th }} 2020$

\section{Introduction}

Domestication is the transformation of wild progenitors to the cultivated species through continues selection for desirable traits of crop plants in order to satisfy the human demand. Domestication is an old practices which was started before 10,000 years through adapting the high yielding varieties with resistance to biotic and abiotic stresses, improved nutritional quality, big seed and fruit size, non-shattering, reduction of seed dispersal mechanisms, a more compact growth habit, early matured crop plants (Gepts, 2004). Crop plants originated from wild species through Mendelian variation, inter-specific hybridization, polyploidy and mutation. Genetic diversity plays an important role in crop improvement because hybridization between lines of diverse origin generally displays a greater heterosis than between, closely related species.

Plant breeding is primarily depends on presence of substantial genetic variation to address the maximum genetic yield potential of the crops and exploitation of this variation through effective selection for improvement (Ribaut, J.M et al., 2002). Hence, plant breeding was launched earlier with plant domestication to develop the superior genotypes in terms of yield, resistance to diseases and insets and other many different traits (Smith, B. D, 1989). Domestication is the evolutionary process in which wild plants genetically, morphologically and physiologically changed by imposing selection for different desires (Harlan et al., 1973). The domesticated crop plant is substantially or greatly altered from its wild to counter part (Rosenthal, J. P.; Dirzo, R, 1997).

Charles Darwin revealed that domestic plant species were different from their wild ancestors in terms of several different traits and ensured the presence of genetic difference between domestic plants and wild populations (Darwin, C, 1859). Many traits in the wild are actually deleterious as compared to domesticate crop plants, as a result, adaptation of wild relatives substantially crucial to increase the suitability to human requirements like yield, taste, storage and cultivation practices. However, fully domesticated crops may not survive in the wild without human intervention in production practices (Crawley et al., 2001). There are strong evidence that revealed crop domestication can profoundly alter interactions among plants and agro-ecologies. These interactions are significantly affected by geographical ranges where the domesticated crops originated. In general, domestication has reduced the genetic variability during selection because of limited number of preferred traits of wild progenitors (Rosenthal J. P, 1997).

Domesticated crop plants are distinguished from their wild progenitors in many different characteristics like 
large-scale chromosomal structural changes (Yang, L et al., 2012), changes in transposable-element content and copy-number variation (Wang, Yet al., 2015). There is higher prevalence of recent polyploidy among major domestic crop species $(34 \%)$ than among wild plant species $(24 \%)$, with monocots exhibiting the most profound difference (Renny-Byfield, S and Wendel, J.F, 2014). Domesticated plants benefitted from the versatility of polyploids (Renny-Byfield, S and Wendel, J.F, 2014), such as broadening of adaptation, increase in harvested organize (gigantism), fixation of heterozygosity, and the appearance of novel traits due to epistatic interactions. Genome duplication can serve as a post zygotic barrier reducing gene flow with wild progenitors (Rosenberg, L.H and Willis, J.H, 2007).

The difference between domesticated plants and their wild progenitors in morphology, physiology and anatomy is known as domestication syndrome. The domestication syndrome is group traits that arise from human preferences for the betterment of domestication practices. Domestication syndrome has reduced genetic diversity associated with the fact that the man used a limited number of wild progenitors to select the desired traits Zohar $e t$ al., 1998). These lost contributed various impediments in further improvements of genetic diversity of crop plants, which considered as the dis advantages of domestication. Agriculture was started along with domestication before 10,000 years ago to achieve the greater demand for food through developing higher yield, resistance to both biotic and abiotic stresses and quality improvement with an opportunity to reach their full genetic potential of crops (Smith, B. D, 2006).

Agriculture faces many challenges of human population growth, climate change, land degradation, malnutrition, poverty, hunger and other stressors. Overcoming these difficult challenges will be harder in the absence plant genetic improvement to increase agricultural productivity through addressing the problem of yield reduction and its links with pest management and climate change (Searchinger, T et al., 2008). However, agriculture must change to meet the rising demand of global population by the transition of agricultural growth to effective modern agricultural development. In this regard, domestication of crop plants was contributing the crucial role through changing the genetic potential of crop plant to the advanced level to reach the molecular marker stages. The practice of improving crop production system with advanced breeding techniques play an important role to alleviate poverty and raise the living standards of the peoples by obtaining better yields of different crops (Lee, C.S et al., 2008). The change from food collection to food production requires domestication of plants (Harlan, J. $\mathrm{R}, 1973$ ). The selective forces that act on plant populations in the original natural environments are to a great extent different from those in the subsequent cultivated environments. In natural environments, strong intra and interspecific competition exists among plants for light, water, and soil nutrients. In contrast, agro ecosystems are characterized by less competition, even in well-known, diverse arrangements like agroforestry (Perfecto and Vander Meer, 2010). Domestication is the transition of the living standard of human being from hunting, gathering to modern agriculture (Smith, 1995a). Domestication is shaped by the interaction of crop plants, environments and cultivators. More studies have clearly indicated how changes in morphology and resistance related traits observed during domestication as well as, environmental interaction greatly affects crop plants in different agro-ecosystem and natural-ecosystem (Doebley, 2006).

The basic requirements and steps of domestication is the presence of natural population with sufficient genetic variation to allow phenotypic variation for traits desirable to humans (Buchman, 2009). Many natural populations of plants have considerable variation that arises from the many natural populations of plants have considerable variation that arises from the geographic distribution and adaptive requirements of the population. Genetic variation in a natural population comes from new combinations of existing genes within a population, mutations, allele migration between populations, natural selection for local adaptation, and random events (Innan, 2004).

Genotypic variation is maintained in natural populations by multiple genetic mechanisms and exposure to diverse environments. Genotypic variation is the fuel for the domestication process and it can be changed during the domestication (Sang, T, 2009). Changing in allelic frequency of desirable traits become frequent during domestication for crop improvement. Different variants of a crop species could evolve into new and new genes from same species, chromosome segments and genes from related species, and novel genes from any species are being introduced to our current crops during modern improvements species (Doebley, 2006). Objective of the paper was to review the role and impact of ecology in domestication of crop plants.

\section{Ecological Approaches to Crop Domestication}

A very broad approach to ecology is required to fill important gaps in understanding of the ecological aspects of domestication. All domesticated crop plants were first domesticated within the native range of their wild progenitors. There were three different major independent fields investigated about the interrelation of geography with plant domestication. The first evidence was the geobotany and genetics of the living plants, secondly, the ${ }^{14} \mathrm{C}$ dated archaeobotanical remains from relevant archaeological sites and third, archaeology of the socio-cultural interaction. The evidence for the earliest domesticated plant remains may enable us to show that domestication itself has been quite rapid and the spread of the domesticated plants started immediately upon domestication (Pasternak, 1998). 
Evolutionary adaptation of crop plants requires the knowledge of the ecology of their wild ancestors and agroecology has great impact in expansion of agriculture over the world (Purugganan, 2009). Plant agriculture is an economic system based on the cultivation of crops regardless of their phenotype and may be supplemented by gathering from the wild. There is too little investigation of crop wild relatives because of the full complexity of cultivated environments from transformation of ecosystem and selective mechanisms to biotic interactions of crop plants with their environments. Evolution under domestication contributes important insights into general questions in evolutionary ecology (Gepts, 2004).

\subsection{Role of ecology in domestication of plants}

Ecology and domestication of crop plants are not separable, where ever the domestication has been practiced. Some of the most important role of ecology in the domestication processes is; ecology elucidates the reason why crop plants more preferably found some geographical region than in others and it also explains why some plant possess characteristics that made them easier to domesticate than others (Gepts, 2008). Since the ecology is place where both wild and domesticated crop plants survive, there is strong association with environmental change and resource acquisition strategies (Diamond, 2002). Wild plants have been domesticated intensively at the center of origin before bringing to other ecologies for cultivation (Hillman and Davies., 1990). This implies to understand the relation of plants to its environments (Casas et al., 2007). Ecology is playing in shaping the traits wild ancestors when they undergo domestication processes (Hillman and Davies., 1990). Archaeological evidence showed that domestication took over a thousand years to get the required characteristics and challenging to take out of adaptation ecology (Tanno and Wilcox 2006).

\subsection{Crop plant Evolution and Domestication}

The term agricultural evolution is summarized all of the changes accumulated in any wild plant form under natural selection, human-mediated artificial selection (domestication), and modern breeding practices. Evolution started from wild form through passing different processes to generate the desired domesticates. A primary concern of agricultural evolution biology is to investigate where, when, and how crop plants originated. Domesticated is the transformation of wild species with certain traits under human selection showing character modifications including novel trait formation and subsequent segregation (H. W. Cai and H. Morishima, 2002). The term domestication is often used to describe the process by which wild becomes stabilized.

Evolution is a gradual change by which the present diversity of plants arose from the earliest and primitive organisms. These changes leading to changes in genetic diversity and availability availabity of the population to undergo evolutionary divergence. The theory of evolution developed by Charles Darwin dictated since 1859, which stated variation exists in initial population of plants and the best adapted individuals survive and reproduce in greater numbers over time (Ellstrand et al., 1999). Indeed, domesticated plants provide alternative materials for evolutionary genetics, such as the genetic basis of traits, the evolution of development and the architecture of genomes (Ross-Ibarra et al., 2007).

\subsection{Differences between Domesticated and Wild Plants}

There are several differences between domesticated and wild relatives. Among the differences are; the genetic diversity of the domesticated crops are low as compared to it wild ancestors because of the ignorance of some wild relatives during intensive selection (M. Pourkheirandish and T. Komatsuda, 2007). The other difference is genetic alteration associated with domestication and genomic changes between the domesticated and wild species is the result of recombination, genetic drift and selection which is totally undergoes evolution to shift the genetic make of the wild relatives over time (Darwin. C, 1859). Charles Darwin observed that the domesticated crops cannot survive in wild because of modification in different morphological, physiological and anatomical traits (Darwin, C 1859). The fundamental distinction associated with domesticated and wild ancestors is the adaptation of crop plants to specific conditions by human labour to meet specific requirements (Darwin. C, 1868). There is also another difference in terms of diseases resistances, competition for light, water, temperature and nutrients, loss of seed dispersal mechanism and photoperiodic control, lack of shattering, different chemical composition and lower toxicity (Casas et al., 2007).

\subsection{Domestication of Plants and Environments}

Plants domesticated in different agro-ecological environments of the world for the different desirable traits that demanded by the cultivators (Mann et al., 1983). Domestication has been conducted since agriculture was started and new plants are taken and moved to be domesticated to new geographical areas of the same or different regions for utilization of different traits after genetic modification (Yen, 1989). People started domesticating environments before cultivation of plants began but, intensive and extensive cultivation of plants led to environmental changes (Yen, 1989). Agricultural expansion has strong impact on the environments by changing genetic diversity of the wild progenitors (Denison et al., 2003). 


\subsection{The Extent of the Domestication of Asexually Reproduced Crop Plants}

As its name indicates asexual reproduction doesn't involve fusion of male and female gametes. Hence, the newly developed plants are not different from their parents. Vegetative propagated crops contribute significantly to the world food supply. The earliest of form of plant breeding is known as domestication in which genetic improvement started. Most of the clonally propagated crops plants in domestication process are neglected despite of their large number of economic contribution (Myers, 1985).

These clonally propagated crops represent tremendous morphological and ecological diversity and they are domesticated for the consumption of roots, tubers, stems, leaves, fruits which most probably used as propagation part to generate new crop plants. As many studies indicated, the great emphasis is given to the domestication of seed propagated crops other than clonally propagated crop plants (doebley, 2004). The extent of domestication of clonally propagated crops is very limited as compared to sexually propagated crops. There several reasons why less attention is given for the domestication of the clonally propagated crops are: First, mutations affecting specific traits of domestication syndrome are selected until they achieve near or full fixation which brings allelic frequencies. Second, clonally propagated crops are not easily undergoing genetic recombination to bring genetic change like other sexually propagated crops (pickers gill, 2007). Third, the presence of limitation in selection for adaptation to new environments from their original centers since the recombination rate is very low (Zohar, 2004). Hence, the domestication of clonally propagated very limited as compared to the sexually propagated crop plants because of the mentioned reasons.

\subsection{World Center of Origin of Cultivated Plants}

All the cultivated crop plants are the product of both natural and artificial selection for extensive modifications for yield, quality, disease resistance and reduced shattering of the seed. The geographic area where domestication began and maximum genetic diversity of crops exists is typically referred to as center of origin for crops. The diversity of crop plants including their wild relatives have been contributing paramount merits in genetic improvement through breeding and selection, in adaptation of crops to diverse environments, as source of genes for resistance to diseases and pests. Vavilov center of origin of a crop plant as the geographic area(s) where it exhibits maximum diversity or where the greatest number of races and botanical varieties occur (Vavilov, N. I, 1926).

Vavilov has made major contribution in identifying eight major center of diversity of crop plants in the world, in proposing the center of origin of crop species coincides with areas where the greatest diversity exists in species, in recognizing secondary centers of origin and pointed out that valuable forms are found far removed from the primary centers of origin and stating in the laws of homologous series in variation, which implies that characters found in one crop species may also expected in similar species (Vavilov, 1951). Center of plant domestication is the area of interest to different researchers as regions of genetic diversity, variability being critical to the success of crop improvement. Being the center of diversity is considered as the center of origin which allows finding new and dominant genes for different breeding purposes (Harlan, J. R, 1973).

Table 1 Summary of centers of origin of cultivated crops (Vavilov's 1926).

\begin{tabular}{|c|l|l|}
\hline S. $N$ & Center Of Origin & Examples Of Cultivated Plant Species \\
\hline I. & Chinese & $\begin{array}{l}\text { Lettuce, Soybean, Turnip, Radish, Eggplant, Peach, Some Citrus, } \\
\text { Apricot, Walnut, Cucumber. }\end{array}$ \\
\hline II. & India (South Asia) & Cucumber, Mango, Cotton, Rice, Orange, Other Citrus, Black Pepper. \\
\hline III. & Indo-Malayan & Banana, Coconut, Yam, Ginger, Nutmeg, Breadfruit. \\
\hline IV. & Central Asia & Almond, Flax, Lentic, Garlic, Carrot, Onion, Pear, Apple, Mustard, Pea. \\
\hline V. & Near East Asia & Apple, Cabbage, Lettuce, Rye, Fig, Pomegranate, Wheat, Barley, Oats \\
\hline VI. & Mediterranean & Celery, Chickpea, Durum Wheat, Beet, Leek \\
\hline VII. & Ethiopia & Castor, Coffee, Sorghum \\
\hline VIII. & Meso-America & Lima Bean Maize, Papaya, Cotton \\
\hline IX. & South-America & Cotton Tomato, Potato, Pumpkin \\
\hline X. & Chile & Potato \\
\hline XI. & Brazilian-Paraguayan & Peanut, Pineapple, Rubber Tree \\
\hline
\end{tabular}

\subsection{Ecological Origin of Crop Plants}

Domestication is the process whereby a population of living organisms is changed at the genetic level through generations of selective breeding and ultimately benefits the interest of human. In the process of bringing wild plant under cultivation to produce crops under the supervision of humans. Since, there is human intervention during the domestication, natural habitat destructed and ecology of the crop plants has great impact on the genetic and phenotypic expression of the potential variation of traits. As several previous study indicated, domesticating crops out of their natural adaptation brought failureties in getting the desired and preferred characteristics by cultivators 
(Darwin. C, 1859)

Table 2 Summary of crop plants along with their ecology

\begin{tabular}{|l|l|}
\hline Ecology & Crops \\
\hline Mediterranean & Wheat, Oat, Rye, Pea Rapeseed, Onion \\
\hline Savanna & $\begin{array}{l}\text { Sorghum, Millets, Soybean, Bean, Peanut, Sunflower, Cotton, } \\
\text { Cassava, Sweet Potato, Banana, Tomato }\end{array}$ \\
\hline Tropical Lowlands Or Tropical Coastal & Coconut \\
\hline Tropical Highlands & Potato \\
\hline Tropical Forests & Sugar Cane, Banana, Oranges, Mango, Coconut \\
\hline Temperate Woodlands & Grapes, Apple, Peach, Sunflower \\
\hline
\end{tabular}

\section{Conclusion}

The transformation of wild ancestors into modern elite cultivars trough domestication and evolution contributes very important role in producing global food and crop plant improvement. The study of the phenotypic variation between wild and domesticated plants presents an opportunity to generate insight into general principles of evolution, using the morphological variation. In the domestication process wild plants have been evolved into crop pants through artificial selection in order to satisfy the specific human demand. Selection exerted by humans on crop plants during the domestication process causes changes in the plants as they transit from wild species to domesticates.

Many traits selected under domestication, for the satisfaction of human needs and as a consequence, fully domesticated crops may not survive in the wild without human intervention in planting and harvesting. Addition of transgenes to highly domesticated crops that cannot survive without human intervention is unlikely to remove the dependency of these crops on humans. The geographic region where domestication began and where most of a crop's genetic diversity resides is typically referred to as the crop's center of origin. Ecology plays a key role in domestication of crop plants starting from the very beginning of evolutionary process and primitive life of human being.

Domestication is a continuous process and bringing wild species of plants by considering the agro-ecological environment plays a significant role for the ease of adaptation. Before domesticating plants to some new areas, consideration of ecology is very critical to maintain yield potential, stability, resistance, tolerance and other important traits that they have in their original place. Generally domestication of crop plants with their appropriate ecologies is used to maintain sustainable yielding ability without reducing actual potential of crop plants.

Wild plants $\longrightarrow$ domestication $\longrightarrow$ Selection $\longrightarrow$ Multiplication $\Rightarrow$ Release $\Rightarrow$ Distribution

\section{REFERENCES}

Alston, J.M., Beddow, J.M. and Pardey, P.G., 2009. Agricultural research, productivity, and food prices in the long run. Science, 325(5945): 1209-1210.

Blumler, M.A., 1996. Ecology, evolutionary theory and agricultural origins. The origins and spread of agriculture and pastoralism in Eurasia, 25-50.

Corinto, G.L., 2014. Nikolai Vavilov's Centers of Origin of Cultivated Plants With a View to Conserving Agricultural Biodiversity.

Crawley, M.J., Brown, S.L., Hails, R.S., Kohn, D.D. and Rees, M., 2001. Biotechnology: Transgenic crops in natural habitats. Nature, 409(6821): 682-683.

Darwin, C, 1868. The Variation of Plants and Animals under Domestication; J. Murray: London, UK.

Darwin, C. The Origin of Species by Means of Natural Selection; J. Murray: London, UK, 1859.

Dempewolf, H., Rieseberg, L.H. and Cronk, Q.C., 2008. Crop domestication in the Compositae: a family-wide trait assessment. Genetic Resources and Crop Evolution, 55(8): 1141-1157.

Denison, R.F., Kiers, E.T. and West, S.A., 2003. Darwinian agriculture: when can humans find solutions beyond the reach of natural selection. The quarterly review of biology, 78(2): 145-168.

Doebley, J. F.; Gaut, B. S.; Smith, B. D,. 2006. The molecular genetics of crop domestication. Cell (127): 13091321.

Doebley, J., 2004. The genetics of maize evolution. Annu. Rev. Genet, (38): 37-59.

Gepts P. 2004. Domestication as a long-term selection experiment. Plant Breed. Rev.24:1- 44

Gepts, P., 2010. Crop domestication as a long-term selection experiment. Plant breeding reviews, 24(2): 1-44.

H. W. Cai and H. Morishima, 2002. QTL clusters reflect character association sin wild and cultivated rice, Theoretical and Applied Genetics, 104(8): 1217-1228.

Hammond, K.A. and Diamond, J., 1997. Maximal sustained energy budgets in humans and animals. Nature, 386(6624): 457- 462.

Harlan, J.R., Wet, J.D. and Price, E.G., 1973. Comparative evaluation of cereals Evolution, 27(2): 311-325. 
Heslop-Harrison, J.S. and Schwarzacher, T., 2007. Domestication, genomics and the future for banana. Annals of botany, 100(5): 1073-1084.

Heywood, V., Casas, A., Ford-Lloyd, B., Kell, S. and Maxted, N., 2007. Conservation and sustainable use of crop wild relatives. Agriculture, ecosystems \& environment, 121(3): 245-255.

Hillman, G.C. and Davies, M.S., 1990. Measured domestication rates in wild wheats and barley under primitive cultivation, and their archaeological implications. Journal of world prehistory, 4(2): 157-222.

Innan, H.; Kim, Y,. 2004. Pattern of polymorphism after strong artificial selection in a domestication event. Proc. Natl. Acad. Sci. U.S.A. (101): 10667-10672.

J. R. Harlan, Crops and Man, 1992. American Society of Agronomy, Crop Science Society of America, Madison, Wis, USA, 2nd edition.

Lee, C.S., Qi, S.H., Zhang, G., Luo, C.L., Zhao, L.Y. and Li, X.D., 2008. Seven thousand years of records on the mining and utilization of metals from lake sediments in central China. Environmental science \& technology, 42(13): 4732-4738.

Lohmueller, K.E., Pearce, C.L., Pike, M., Lander, E.S. and Hirschhorn, J.N., 2003. Meta-analysis of genetic association studies supports a contribution of common variants to susceptibility to common disease. Nature genetics, 33(2): 177-182.

M. Pourkheirandish and T. Komatsuda, 2007. The importance of barley genetics and domestication in a global perspective, Annals of Botany, 100(5): 999 - 1008.

McKey, D.B., Elias, M., Pujol, B. and Duputie, A., 2012. Ecological Approaches to Crop Domestication. Biodiversity in agriculture: domestication, evolution, and sustainability, 377.

Meyer, R.S.; DuVal, A.E.; Jensen, 2012. H.R. Patterns and processes in crop domestication: An historical review and quantitative analysis of 203 global food crops. New Phytol, (196): 29 - 48.

Pasternak, R.1998. Investigation of botanical remains from Nevali C, ori, PPNB, the Origins of Agriculture and Crop Domestication, 170-177.

Pickers gill, B., 2007. Domestication of plants in the Americas: insights from Mendelian and molecular genetics. Annals of botany, 100(5): 925-940.

Purugganan, M. D.; Fuller, D. Q,. 2009. The nature of selection during plant domestication. Nature (457): 843-848.

Renny-Byfield, S.; Wendel, J.F., 2014. Doubling down on genomes: Polyploidy and crop plants. Am. J.Bot., (101): 1711-1725.

Ribaut, J.M., Banziger, M., Betran, J., Jiang, C. and Edmeades, G.O., 2002. Breeding: Drought Tolerance Improvement in Tropical Maize. Quantitative genetics, genomics, and plant breeding, 85.

Rieseberg, L.H.; Willis, J.H. Plant Speciation,. 2007. Science, (317): 910- 914.

Rosenthal, J. P.; Dirzo, R,. 1997. Effects of life history, domestication and agronomic selection on plant defence against insects: evidence from maize and wild relatives. Ecol, (11): 337-355.

Ross-Ibarra, J., Morrell, P.L. and Gaut, B.S., 2007. Plant domestication, a unique opportunity to identify the genetic basis of adaptation. Proceedings of the National Academy of Sciences, 104(1): 8641-8648.

Sang, T,. 2009. Genes and mutations underlying domestication transitions in grasses. Plant Physiol. (149): 63-70.

Searchinger, T., Heimlich, R., Houghton, R.A., Dong, F., Elobeid, A., Fabiosa, J., Tokgoz, S., Hayes, D. and Yu, T.H., 2008. Use of US croplands for biofuels increases greenhouse gases through emissions from land-use change. Science, 319(5867): 1238-1240.

Smith, B. D., 1989. Origins of agriculture in Eastern North America. Science (246): 1566 -1571.

Smith, B.D., 1995. The emergence of agriculture Scientific American Library series. Scientific American Library, New York Google Scholar.

Tenaillon, M. I: U'Ren, J: Tenaillon, O: Gaut, B. S, 2004. Selection versus demography: a multilocus investigation of the domestication process in maize, (21): 1214-1225.

Vavilov, N. I,. 1926. Studies on the origin of cultivated plants. Bull. Appl. Bot. 16.

Wang, Y.; Xiong, G.; Hu, J.; Jiang, L.; Yu, H.; Xu, J.; Fang, Y.; Zeng, L.; Xu, E.; Xu, J., 2015. Copy number variation at the GL7 locus contributes to grain size diversity in rice. Nat. Genet. 47: 944- 948.

Yang, L.; Dal-Hoe, K.; Yuhong, L.; Xuejiao, Z.; Feishi, L.; Havey, M.J.; Jiming, J.; Yiqun, W., 2012. Chromosome rearrangements during domestication of cucumber as revealed by high-density genetic mapping and draft genome assembly. Plant J. (71): 895-906.

Zeder, M.A., 2015. Core questions in domestication research. Proceedings of the National Academy of Sciences, 112(11): 3191-3198

Zohary, D., 2004. Unconscious selection and the evolution of domesticated plants. Economic botany, 58(1): 5-10. 